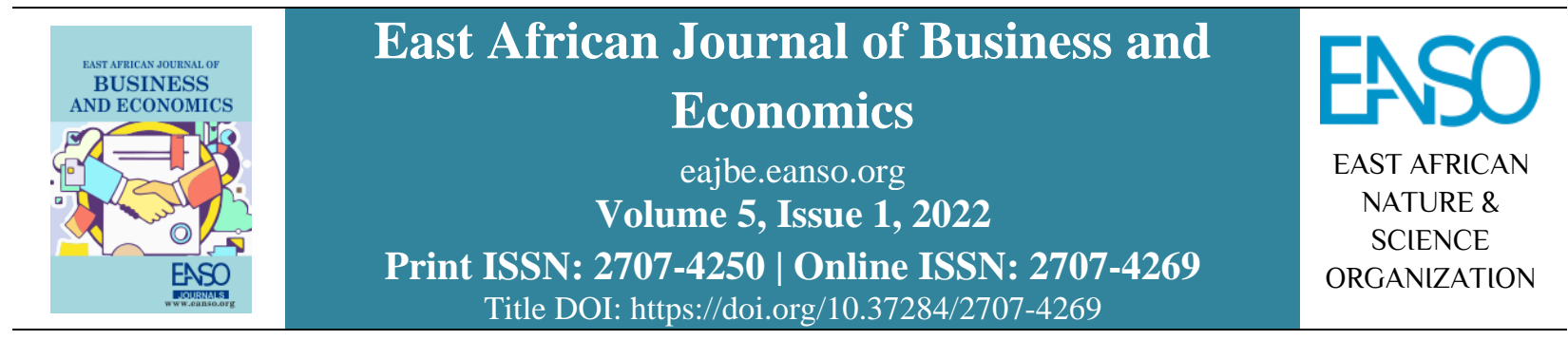

Original Article

\title{
Examining the Effect of Knowledge Management on Performance of Small Firms in Dare es Salaam: A Case Study of Garage Workshops in Temeke District, Dar es Salaam, Tanzania.
}

\author{
Pius Sotery ${ }^{1 *} \&$ Dr. Hawa I. Munisi, PhD \\ ${ }^{1}$ Institute of Accountancy Arusha, P.O.Box 2798. Njiro Hill, Arusha, Tanzania. \\ ${ }^{2}$ Institute of Finance Management, P.O Box 39185 Shaaban Robert Street, Dar es Salaam, Tanzania \\ *Correspondence email: sotery.pius83@gmail.com
}

Article DOI: https://doi.org/10.37284/eajbe.5.1.549

\section{Date Published: ABSTRACT}

14 February 2022 Despite knowledge management being an approach used to achieve organisational objectives by making the best use of knowledge, little has been

Keywords: done on identifying the effect of knowledge management in the Tanzanian context. This study was therefore undertaken to assess the impact of knowledge Knowledge, management on the performance of small firms in Tanzania. Three variables, Knowledge knowledge creation, knowledge sharing, and knowledge utilisation were examined for their impact on the performance of garage workshops. The Knowledge Sharing, researcher used a random sampling technique in recruiting the sample size. Knowledge Sharing, Questionnaires and interviews were used in obtaining the data. Content Knowledge Utilization, analysis, descriptive statistics, and multiple regression analysis were used to Garage Performance. analyse study data. The study found that knowledge creation and knowledge utilisation were positively and significantly related to the performance of garage workshops, while knowledge sharing was found to have a positive but insignificant impact on garage workshops performance. Management of small firms was recommended to hire experienced staff to encourage knowledge creation, create an organisational culture that encourages workers interaction, and arrange tasks in a way that workers are encouraged to utilise new knowledge.

\section{APA CITATION}

Sotery, P., \& Munisi, H. I. (2022). Examining the Effect of Knowledge Management on Performance of Small Firms in Dare es Salaam: A Case Study of Garage Workshops in Temeke District, Dar es Salaam, Tanzania. East African Journal of Business and Economics, 5(1), 48-61. https://doi.org/10.37284/eajbe.5.1.549

\section{CHICAGO CITATION}

Sotery, Pius \& Hawa I. Munisi. 2022. "Examining the Effect of Knowledge Management on Performance of Small Firms in Dare es Salaam: A Case Study of Garage Workshops in Temeke District, Dar es Salaam, Tanzania". East African Journal of Business and Economics 5 (1), 48-61. https://doi.org/10.37284/eajbe.5.1.549.

48 | This work is licensed under a Creative Commons Attribution 4.0 International License. 


\section{HARVARD CITATION}

Sotery, P., \& Munisi, H. I. (2022) "Examining the Effect of Knowledge Management on Performance of Small Firms in Dare es Salaam: A Case Study of Garage Workshops in Temeke District, Dar es Salaam, Tanzania”, East African Journal of Business and Economics, 5(1), pp. 48-61. doi: 10.37284/eajbe.5.1.549.

\section{IEEE CITATION}

P. Sotery, \& H. I. Munisi, "Examining the Effect of Knowledge Management on Performance of Small Firms in Dare es Salaam: A Case Study of Garage Workshops in Temeke District, Dar es Salaam, Tanzania”, EAJBE, vol. 5, no. 1, pp. 48-61, Feb. 2022.

\section{MLA CITATION}

Sotery, Pius \& Hawa I. Munisi. "Examining the Effect of Knowledge Management on Performance of Small Firms in Dare es Salaam: A Case Study of Garage Workshops in Temeke District, Dar es Salaam, Tanzania". East African Journal of Business and Economics, Vol. 5, no. 1, Feb. 2022, pp. 48-61, doi:10.37284/eajbe.5.1.549.

\section{INTRODUCTION}

In the present hypercompetitive environment, knowledge management processes and international entrepreneurship orientations have become the most engaging concept in management (Hanif et. al., 2018). Both are predominantly the common strategies for better organisational performance. Byukusenge \& Munene (2017), described the knowledge management process as consisting of the acquisition of knowledge, sharing, and utilisation of the acquired knowledge. Knowledge in businesses can be acquired simply through social processes between a firm and local stakeholders or selfgeneration of new knowledge in the process of research and development. Different studies have proposed that organisations applying knowledge management can bring out superior performance. The importance of knowledge management can also be observed in the stimulation of innovation, especially in the present increasingly interacting and deregulated business environment as a result of globalisation.

Despite the notion that knowledge management is simple, most micro and small organisations in developing countries have a long way to go in order to operate as 'knowledge foundation organizations'. For instance, literature has scarce information on the nature, methods and concepts of knowledge management in the developing World while strategies on viable organisation structure and corporate values for competition is absent as well (Karlenzig, 2014).Several researches have established that successful knowledge management leads to the creation of distinct competencies and capabilities, which leads to improvement in the performance of the business. Ben Zaied et. al. (2015), indicated a close relationship between knowledge management, innovation and business performance.

Most entrepreneurial ventures in the developing economies are faced with scarce resources, capability, and viable environment that support knowledge creation and sharing (Ferreira et. al., 2017; Ritala et. al., 2015; Siegel and Renko, 2012; Wasko and Faraj, 2005),. Thus, in order to develop organisations endowed with the capability to gain, store and share information for the achievement of competitive advantage, management of knowledge in small and medium enterprises is a necessity.

The main objective of the study was to examine the effect of knowledge management on the performance of garage workshops. Specifically, the study focused on the effect of knowledge creation; the effect of knowledge sharing; and the effect of knowledge utilisation on the performance of garage workshops in Temeke district covering Chang'ombe, Tandika, Keko, Mbagala and Yombo Vituka wards.

This study shall be useful to entrepreneurs, technical businesses, policymakers, companies that provide technical services, and innovation centres to appreciate the role of Knowledge Management in performance. Information obtained shall be useful for garage workshops to improve performance through Knowledge Management. The researcher 
shall ensure this by sharing the findings of this report with some of the stakeholders of garage workshops.

This paper is comprised of the first section which exhibits the background of the study followed by a theoretical review part. The third part exhibits the empirical review section, followed by a fourth part which highlights the methodology used in this study. The fifth section of this paper shows the conclusion gathered from the findings of the study. The following section is the recommendation section which provides suggestions for stakeholders in the management and employee position as per the findings of this study. The last section is the reference section which shows sources of study materials that were reviewed in the undertaking of this study.

\section{THEORETICAL REVIEW}

In the theoretical review, a brief look at models and theories related to knowledge management is reviewed.

\section{Aldrich and Yang, 2014 Model for Knowledge Creation}

Aldrich and Yang(2014) argued that entrepreneurs need to acquire the knowledge they need to organise new businesses. And knowledge acquisition is a life-long learning process for entrepreneurs ranging from their socialisation as children, adolescents and continuing through their early work. They highlighted that entrepreneurial knowledge is vital to explaining the survival and growth of new ventures. Entrepreneurs should understand "knowhow," "know what," and "know who" knowledge. Aldrich and Yang (2014) developed the following model

\section{Dana Sensuse Model for Knowledge Sharing}

Sensuse and Bulan (2013) indicated that knowledge sharing takes place at an individual and organisational level. For individual employees, knowledge sharing is communicating with their colleagues to help things get done better, faster, and more efficiently. Organizational-wise, knowledge sharing is to capture, organise, re-use, and share experience-based knowledge to make knowledge available that it can be used by others in the business

Knowledge transferred will benefit not only the organisation but also individuals by improving their competence through the improvement of the development and performance of an organisation (Minbaeva, et. al.,2014; Bulan \& Sensuse, 2013). Accordingly, entrepreneurial firms that show limitations in resources and manpower benefit by securing more diverse resources from external sources by adopting open innovation strategies (Yun and Mohan, 2012). 
East African Journal of Business and Economics, Volume 5, Issue 1, 2022

Article DOI: https://doi.org/10.37284/eajbe.5.1.549

Figure 1: The Aldrich and Yang model of Knowledge Creation

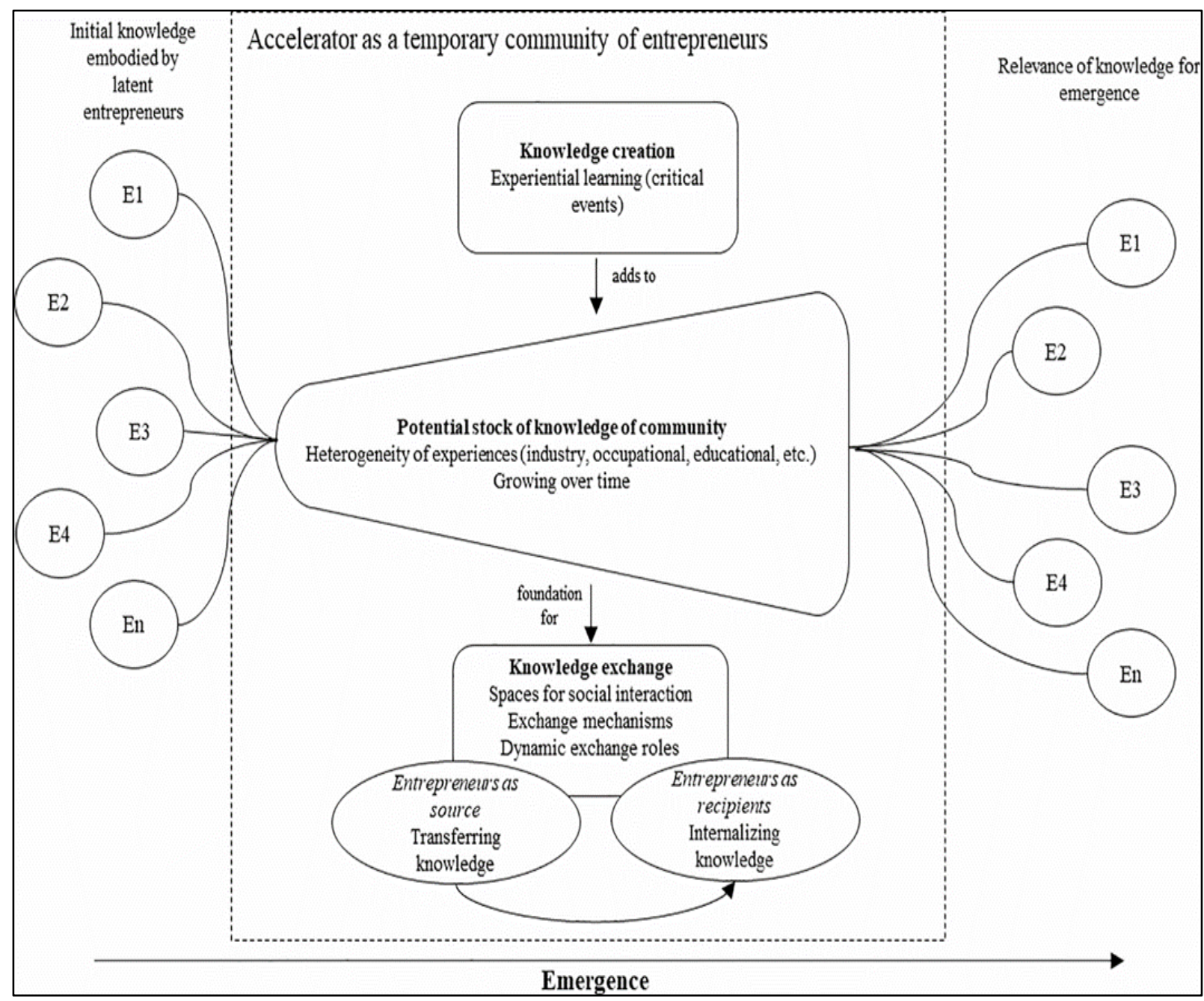

Source: Aldrich and Yang, (2014).

51 This work is licensed under a Creative Commons Attribution 4.0 International License. 
Figure 2: Dana Sensuse Model of Knowledge Sharing

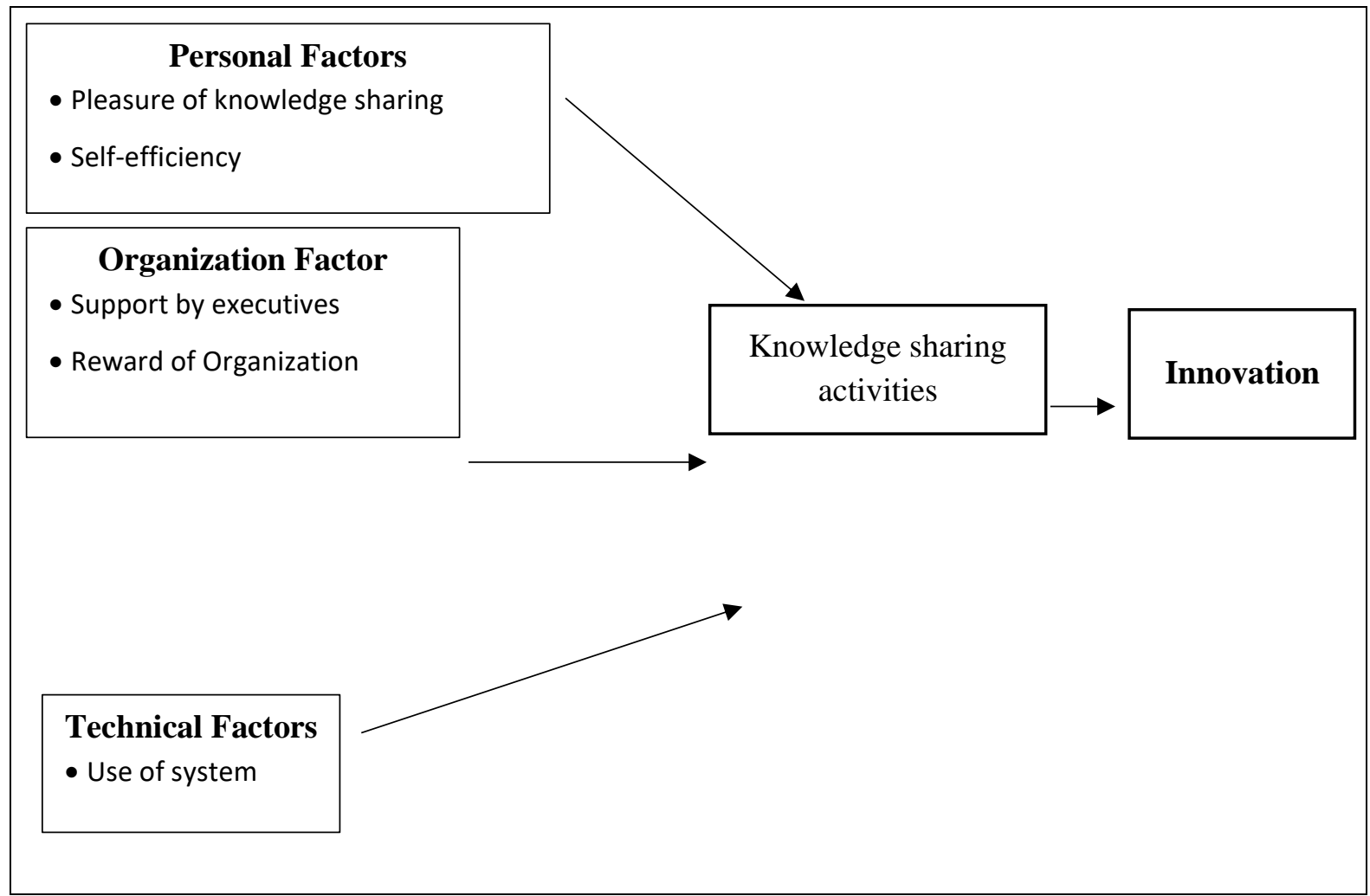

Source: Bulan \& Sensuse (2013)

\section{EMPIRICAL REVIEW}

Empirical studies have found the relationship between knowledge creation and organisational performance (Shahbakhsh, 2013; Derakhshan et. al., 2020; Abtahi et. al, Azari et. al.,2013; Berraies and Chaher, 2014). Mills and Smith (2011) mentioned that organisations not only need to plan their tangible assets effectively but are also required to operationalise information properly to become successful. An organisation's capability to generate new knowledge is contingent upon the ability to create new knowledge (Nonaka and Takecuhi, 2015).

Superior application of knowledge creation process enables an organisation to link new knowledge in innovative ways that enhance customer value through augmenting market offerings of the organisations (Huang et al., 2009). According to Yong et al. (2009), firms that are better at creating knowledge through the SECI process are more successful in attaining capability, growth, and yield. Hence, knowledge creation is key to improving organisational performance (Huang et al., 2009).

Gholami et al. (2013) in a study on SMEs found that organisations need to create and implement new technology to facilitate strategic decision making that leads to improvement in productivity, financial and staff performance, innovation, work relationships, and customer satisfaction. Nawab et al. (2015) found that knowledge creation generates innovation in the banking industry which ultimately improves organisational performance.

Berraies and Chaher (2014) ascertain that the knowledge creation process is a catalyst for firms' innovation. The authors concluded that socialisation has the strongest influence on innovation performance. Laeeque and Babar (2017) also confirm that knowledge creation leads to 
improvement in firm performance due to the development in innovation capability. Nguyen et al. (2018) argued that inculcating knowledge creation does not lead to organisational performance unless it transforms into product innovation. Chung et al. (2019) conclude that knowledge creation based on agility improves organisational creativity which subsequently results in superior organisational performance.

Chang, Liao, and Wu (2017) empirically justified that knowledge creation activities positively influence organisational performance. Knowledgecreation systems and practices create new process knowledge and, thus, are influential in achieving superior, competitive firm performance (Alegre et al., 2013). Knowledge creation facilitates knowledge exchange and knowledge use which decidedly influences knowledge use, exchange, and utilisation of knowledge. Knowledge utilisation, exchange, and use of knowledge decidedly influence organisational learning. Knowledge segments and organisational learning havea strong relationship with business development and organisational performance (Sarand etal., 2015; Ramirez and Kumpikaite, 2012) also delivers his opinion in favour of the knowledge creation process in improving organisational performance since this kind of activities aid in extracting and utilising knowledge of different members of the organisational supply chain which ultimately provides firms with an opportunity to achieve profit, growth, efficiency, and sustainable competitive advantages.

Zargar, E., \& Rezaee, M. (2014) in a study entitled The study of knowledge management effect on performance rate of employees concluded that, organisations which properly implement knowledge management from three perspectives of customers, employees and market will achieve the acceptable improvement in customer relationship management in his organisation.
Nikabadi (2014) in a study notes that he existing processes and indicators in the framework have been analysed through the factor analysis technique. Results showed that all of these processes are necessary for the supply chain and the order of importance is: 1) Transfer, share, and distribution 2) Utilisation, application and exploitation, 3) Acquisition, creation, and production of knowledge 4) Organising, storage 5) evaluation and feedback

Akhavan et al. (2011) in their research interviewed 9 managers of top public universities who had at least the management post of faculty dean. The qualitative data analysis results supported the existence of principal components and subcomponents in the model. The direct effect of knowledge management strategies on universities' performance was rejected and this effect is through critical success factors and knowledge management actions. It was also revealed that the impact of knowledge management strategies on knowledge management practices in university is only through critical success factors. This model can help to understand the components of knowledge management and can suggest a practical guide for the successful deployment of knowledge management in higher education in Iran.

Taghizadeh and Shokri's study (2015) on knowledge management infrastructures and status in Tabriz University from the perspective of faculty members", concluded that the familiarity rate of the research community with the concept of knowledge management is at the low level. Among the examined infrastructural factors, four factors of organisational culture, organisational structure, processes, and financial resources are in inappropriate condition and two factors of manpower and technology are inappropriate condition

\section{CONCEPTUAL FRAMEWORK}

The conceptual framework provides a written illustration of the expected relationship between 
variables of the study. The conceptual framework for this study is represented by the following

illustration:

Figure 3: Conceptual framework

Independent Variable

\begin{tabular}{|c|}
\hline Knowledge Creation \\
- Training \\
- Self-experience \\
Knowledge Sharing \\
$>$ Communication and Interactions \\
$>$ Job rotation \\
$>$ Diaspora induction \\
Knowledge Utilization \\
* Quality of services delivery \\
Consistence performance \\
Cost Analysis on service
\end{tabular}

\section{RESEARCH METHODOLOGY}

This study employed a mix of qualitative and quantitative research designs. Qualitative analysis and mathematical estimations were involved in concluding the study. In qualitative analysis, content analysis was used to analyse the data collected by interview method, while descriptive and regression analysis was used to analyse data collected by questionnaires.

The target population is all workers in garage workshops located in Temeke district which used is the entire staff is amounting to 100 employees. A sample size of 50 employees was extracted from the formula:

$$
n=\frac{N}{\left(1+N e^{2}\right)}
$$

\section{Dependent Variables}

Garage Workshop Performance

- Customer Satisfaction

- Accessibility of Service

- Timeline of Service
The following regression model was employed:

$$
Y=\alpha+\beta_{1} X_{1}+\beta_{2} X_{2}+\beta_{3} X_{3}+\epsilon
$$

Where $\mathrm{Y}=$ Dependent variable (Performance of garage workshops) to be influenced by any change in independent variables $\mathrm{X} 1, \mathrm{X} 2$, and $\mathrm{X} 3 . \mathrm{Y}=$ Workshop Garage Performance; $\mathrm{X}_{1}=$ Knowledge Creation; $X_{2}=$ Knowledge Sharing; $X_{3}=$ Knowledge Utilization; $\alpha=$ the constant term, while the coefficient; $\beta=1 \ldots 5$ was used to measure the sensitivity of the dependent variable $(\mathrm{Y})$ to a unit change in the predictor variables $X_{1}, X_{2}, X_{3} ; \varepsilon$ is the error term which captures the unexplained variation in the model.

\section{STUDY FINDINGS}

This section presents and discusses the research findings to explain how the studied determinants

54 | This work is licensed under a Creative Commons Attribution 4.0 International License. 
East African Journal of Business and Economics, Volume 5, Issue 1, 2022

Article DOI: https://doi.org/10.37284/eajbe.5.1.549

influence the share price of domestic-listed companies.

Descriptive analysis of questionnaires showed that there was a $100 \%$ response rate from both questionnaires and interviews. Findings showed that, on average, $10 \%$ of the respondents agreed, $50 \%$ agreed, $32 \%$ were neutral, $8 \%$ disagreed, while $0 \%$ strongly disagreed that the independent variables, knowledge creation, knowledge sharing, and knowledge utilisation influenced garage workshop performance (Table 1).

Table 1: Garage Performance

\begin{tabular}{|c|c|c|c|c|c|}
\hline Statements / items & SA & $\mathbf{A}$ & $\mathbf{N}$ & D & SD \\
\hline $\begin{array}{l}\text { Knowledge creation improves customer satisfaction, accessibility } \\
\text { of service, and timeline of services }\end{array}$ & $18 \%$ & $56 \%$ & $12 \%$ & $8 \%$ & $6 \%$ \\
\hline $\begin{array}{l}\text { Knowledge sharing within the organisation improves customer } \\
\text { satisfaction, accessibility of service, and timeline of services }\end{array}$ & $30 \%$ & $54 \%$ & $6 \%$ & $8 \%$ & $2 \%$ \\
\hline $\begin{array}{l}\text { Knowledge Utilisation improves customer satisfaction, } \\
\text { accessibility of service, and timeline of services }\end{array}$ & $24 \%$ & $62 \%$ & $8 \%$ & $6 \%$ & $0 \%$ \\
\hline
\end{tabular}

Respondents from the interview were on average on the view that knowledge creation through experience and training played an important role in the performance of the garages. They also reported a view that interaction between workers and job rotations played a key role in the sharing of knowledge to improve garage performance while improving the service quality. Consistency of performance was observed after utilising the acquired knowledge and was meant to improve garage performance.

Table 2: Regression of Knowledge variables against garage performance

\begin{tabular}{|c|c|c|c|c|c|}
\hline \multirow[t]{2}{*}{ Model } & \multicolumn{2}{|c|}{$\begin{array}{l}\text { Unstandardised } \\
\text { Coefficients }\end{array}$} & \multirow{2}{*}{$\begin{array}{l}\text { Standardised } \\
\text { Coefficients } \\
\text { Beta } \\
\end{array}$} & \multirow[t]{2}{*}{$\mathbf{t}$} & \multirow[t]{2}{*}{ Sig. } \\
\hline & B & Std. Err & & & \\
\hline \multicolumn{6}{|l|}{ Knowledge creation regression analysis } \\
\hline (Constant) & 2.367 & .504 & & 4.700 & .000 \\
\hline Through on job training & .328 & .136 & .047 & 2.417 & .043 \\
\hline Through working experience & .212 & .090 & .010 & 2.365 & .048 \\
\hline Through training & .023 & .127 & .027 & .177 & .860 \\
\hline R-Squire $=0.563 \quad$ Adj R-Squire & $=0.580$ & & 0.029 & & \\
\hline \multicolumn{6}{|c|}{ Knowledge Sharing Regression Analysis } \\
\hline (Constant) & 2.022 & .435 & & 4.648 & .000 \\
\hline Through daily workers interaction & .297 & .093 & .030 & 3.198 & .014 \\
\hline Through periodic job rotation & .022 & .094 & .037 & .234 & .616 \\
\hline Through diasporas & .071 & .111 & .101 & 639 & .526 \\
\hline $\mathrm{R}$-Squire $=0.461 \quad$ Adj R-Squire & $=0.480$ & & 0.046 & & \\
\hline \multicolumn{6}{|c|}{ Knowledge Utilization Regression Analysis } \\
\hline (Constant) & 2.430 & .543 & & 4.477 & .000 \\
\hline Improved quality of service & .300 & .110 & .107 & 2.728 & .041 \\
\hline $\begin{array}{l}\text { Consistence of a certain level of } \\
\text { performance }\end{array}$ & .037 & .091 & .061 & .410 & .684 \\
\hline
\end{tabular}

55 | This work is licensed under a Creative Commons Attribution 4.0 International License. 
East African Journal of Business and Economics, Volume 5, Issue 1, 2022

Article DOI: https://doi.org/10.37284/eajbe.5.1.549

\begin{tabular}{|c|c|c|c|c|c|}
\hline \multirow[t]{2}{*}{ Model } & \multicolumn{2}{|c|}{$\begin{array}{l}\text { Unstandardised } \\
\text { Coefficients }\end{array}$} & \multirow{2}{*}{$\begin{array}{l}\text { Standardised } \\
\text { Coefficients } \\
\text { Beta } \\
\end{array}$} & \multirow[t]{2}{*}{$\mathbf{t}$} & \multirow[t]{2}{*}{ Sig. } \\
\hline & B & Std. Err & & & \\
\hline $\begin{array}{l}\text { Analysis of time, work complexity and } \\
\text { anticipated costs }\end{array}$ & .390 & .107 & .095 & 3.646 & .021 \\
\hline R-Squire $=0.474$ & Adj R-Squire $=0.508$ & \multicolumn{2}{|c|}{ Sig $=0.023$} & & \\
\hline
\end{tabular}

a. Dependent Variable: Garage workshop performance

Findings from regression showed that the model employed in the study was significant considering the p-value of 0.02 from regression results. The $R$ square value of the model indicated that the study independent variables, knowledge creation, knowledge sharing, and knowledge utilisation were able to explain the dependent variable, garage workshop performance by $60.2 \%$ (Table 3 ).

Table 3: Overall Regression Analysis

\begin{tabular}{|c|c|c|c|c|c|}
\hline \multirow[t]{2}{*}{ Model } & \multicolumn{2}{|c|}{$\begin{array}{l}\text { Unstandardised } \\
\text { Coefficients }\end{array}$} & \multirow{2}{*}{$\begin{array}{l}\text { Standardised } \\
\text { Coefficients } \\
\text { Beta } \\
\end{array}$} & \multirow[t]{2}{*}{$\mathbf{t}$} & \multirow[t]{2}{*}{ Sig. } \\
\hline & B & Std. Error & & & \\
\hline (Constant) & 2.378 & 678 & & 3.506 & .001 \\
\hline Knowledge creation & .121 & .181 & .085 & 2.572 & .047 \\
\hline Knowledge sharing & .142 & .128 & .165 & 1.110 & .273 \\
\hline Knowledge utilization & .414 & .173 & .057 & 2.395 & .049 \\
\hline R-Squire $=0.602 \mathrm{Adj}$ R-Squire $=0.631$ & \multicolumn{2}{|c|}{$\operatorname{Sig}=0.002$} & & & \\
\hline
\end{tabular}

Knowledge creation was found to be positively and significantly related to the performance of garage workshops in Temeke. On the other hand, knowledge sharing was found to be positively related to garage workshop performance, but the relationship was found to be insignificant. Lastly, Knowledge utilisation was also found to have a positive and significant relationship with the performance of garage workshops in Temeke.

\section{DISCUSSION OF THE FNDINGS}

From the regression results, it was indicated that knowledge creation was positively and significantly related to the performance of garage workshops. That is, when the garage management improves knowledge creation among its staff, the performance of the garage is expected to improve as well. The findings reflect Omotayo (2015) who indicated that new knowledge that emerges from the knowledge creation process helps organisations to develop their ability to generate new knowledge, innovate, and add value. This new knowledge fosters developing a new and innovative product, improving internal processes, or enhancing organisations' performance.

Garage workshops in Temeke districts upon searching for ways to improve their performance should work on developing a good knowledge creation system especially by offering on-job training for both new and existing works as well as hiring well-experienced staff because these two methods are significant modes of knowledge creation that influence the performance of garage workshops. On the other hand, even though selfcreation of knowledge was not found to be significant, garage management needs to emphasise it to stimulate innovation. This is because innovation can provide new and more effective ways to perform the job and offer better services.

Additionally, a positive and significant relationship between knowledge sharing and garage 
performance places sharing of knowledge as one of the important parts of knowledge management that contribute to the performance of garage workshops in Temeke. From the regression analysis, it was indicated that one method of knowledge sharing, namely workers' interaction is most effective in impacting the performance of garage workshops; therefore, garages in Temeke can use this method to boost their performance than they use other knowledge sharing methods such as job rotations and using Diaspora. Laycock (2005) explained that an important element of knowledge sharing that improves performance is the network which encourages people to work less formally; therefore, creating relationships that lead to more cooperation and collaboration.

Similar to this view is the study of Byukusenge \& Munene (2017) which also indicated that interaction between workers in the firm influences' knowledge sharing and improves the performance of the firm. This was reported to happen because of the continuous knowledge sharing that occurs when workers between departments interact with one another leading to diversified knowledge in staff.

Contrary to the findings of this study, the findings of Ben Zaied, Louati, and Affes (2015) show that job rotation enhances performance by giving employees a better working experience. They found out that job rotation widens employees' knowledge on different sections. Therefore, employees' productivity is enhanced and hence the overall performance.

Lastly, this study reported a significant positive effect of knowledge utilisation on the performance of garage workshops. Among the variables of knowledge utilisation, the study indicated that in Temeke, the garage workshops performance was influenced by improved quality of services and cost and time analysis of the job. Similar to this finding is shown in the study of Nawab et al. (2015) who reported that improved quality of services led to the improved performance of firms in terms of reliability and time taken to complete the service.

This finding was supported by Byukusenge \& Munene (2017) who indicated that it is the utilisation of knowledge that improves the performance of firms, not the mere creation and sharing. Their study concluded that knowledge utilisation is the most important part of knowledge management since it stimulates and leads to innovation which allows the company to perform better among its peers.

\section{CONCLUSION}

Based on the findings, we conclude that knowledge creation is an important part of knowledge management and it significantly and positively influences the performance of Garage workshops in Temeke District. The methods of knowledge creation that are highly impactful on the performance of Temeke garages were on the job training and one's experience. Firms can emphasise self-creation of knowledge for many purposes, but it was not found to be of significance in improving the performance of the garages.

Knowledge sharing, on the other hand, despite exerting a positing influence on the performance of garages in Temeke, was not significant as a whole. However, one element of knowledge sharing, namely workers' interaction, was found to significantly influence garage performance. Thus, even though garage management is safe to ignore knowledge sharing as a means of improving garage performance, management should encourage interaction between workers of various departments to boost the diversification of knowledge within the firm.

Lastly, knowledge utilisation is positively and significantly related to the performance of garages in Temeke. Performance is influenced by knowledge utilisation through improved quality of provided services after utilisation of acquired 
knowledge and thorough analysis of costs, time, and complexity of the work performed.

\section{Recommendation and Policy Implications}

Based on the findings of the study, the study recommended that garage workshop managers should improve the in-house knowledge management system as a means to better the performance of garages. On knowledge, creation managers are encouraged to offer training to existing as well as new workers to ensure that all workers are well informed about the job and its procedures. This way, workers will be able to perform the job correctly and hence improve the performance.

Not only that but also managers are recommended to hire a significant number of experienced workers because the experience was found to be a significant influence on garage performance. Experienced workers do not only help train new and less experienced workers, but they also increase the level of accuracy of the job performed, which impacts the performance of the garage in general. By supporting and promoting individuals with the appropriate knowledge and capabilities, they allow them to become role models and encourage local influence.

Additionally, managers too are recommended to arrange tasks in such a way that encourages workers to interact with others. More effectively, managers should arrange tasks in a way that allows workers to rotate between departments to acquire and share knowledge with others. Managers should also apply knowledge, management tools, and programs to promote a culture that boosts workers' interaction.

One of the major barriers to knowledge management is that people do not want to share their knowledge for any reason and use it exclusively for their personal development because there may be a misconception that since knowledge is power, it should not be given freely. Cultural factors in the organisation, such as the creation of work teams and the sharing of work and trust among employees, will allow the flow of knowledge to spread freely throughout the organisation and will also play an important role in the creation, acquisition, and dissemination of knowledge. Therefore, it is recommended that organisations give employees more freedom to act, individuals collaborate more in doing their work, and managers try to build a closer relationship between employees.

Lastly, since knowledge utilisation was found to be significant and highlighted by other scholars such as Byukusenge \& Munene, 2017 and Liao \& Barnes, 2015) as the most important part of knowledge management, workers are recommended to make use of acquired knowledge. This is because, without utilisation, the impact of knowledge creation and sharing on the performance of the garages is minimal if any.

Managers, on the other hand, are recommended to set tasks that encourage the use of newly acquired knowledge to ensure that workers in one way or another practice on new knowledge to make it impactful. This will also stimulate innovation as workers will be able to consolidate previously held knowledge and new knowledge and possibly create new ways of performing their job.

\section{REFERENCES}

Abtahi, M. S.,Azari, H., \& Moghaddam, B. A. (2013). The influence of key factors of knowledge management on improvement of its administrative processes (A case study of the regional electric company of Khorasan). International Journal of Management, IT and Engineering, 3(8), 427-448.

Akhavan, A., Owlia, M. S., Jafari, M., \& Zare, Y. (2011, December). A model for linking knowledge management strategies, critical success factors, knowledge management practices and organizational performance; the case of Iranian universities. In 2011 IEEE International Conference on Industrial 
Engineering and Engineering Management (pp. 1591-1595). IEEE.

Aldrich, H. E., \& Yang, T. (2014). How do entrepreneurs know what to do? Learning and organising in new ventures. Journal of Evolutionary Economics, 24(1), 59-82.

Alegre, J., Sengupta, K., \& Lapiedra, R. (2013). Knowledge management and innovation performance in a high-tech SMEs industry. International small business journal, 31(4), 454470 .

Ben Zaied, R. M., Louati, H., \& Affes, H. (2015). The relationship between organisational innovations, internal sources of knowledge and organisational performance. International Journal of Managing Value and Supply Chains, 6(1), 53-67.

Berraies, S., \& Chaher, M. (2014). Knowledge creation process and firms' innovation performance: Mediating effect of organizational learning. International journal of human resource studies, 4(1), 204.

Byukusenge, E., \& Munene, J. (2017). Knowledge management and business performance: Does innovation matter? Cogent Business \& Management, 1-18.

Chang, W. J., Liao, S. H., \& Wu, T. T. (2017). Relationships among organizational culture, knowledge sharing, and innovation capability: a case of the automobile industry in Taiwan. Knowledge Management Research \& Practice, 15(3), 471-490.

Chung, M. (2019). Improving Efficiency on Technologies: University of Michigann.

Derakhshan, M.,Rezaei, S., Pourkiani, M., \& Bigzadeh, F. (2020). Knowledge Management, Knowledge processing Style, Task, Organizational Culture, Organization Structure, Information Technology, Organization size.
Quarterly Journal of Public Organzations Management, 8(2), 25-38.

Ferreira, J. J., Ratten, V., \& Dana, L. P. (2017). Knowledge spillover-based strategic entrepreneurship. International Entrepreneurship and Management Journal, 13(1), 161-167.

Gholami, M. H., Asli, M. N., Nazari-Shirkouhi, S., \& Noruzy, A. (2013). Investigating the influence of knowledge management practices on organizational performance: an empirical study. Acta Polytechnica Hungarica, 10(2), 205-216.

Hanif, M. I., Malik, F., \& Hamid, A. B. A. (2018). The effect of knowledge management and entrepreneurial orientation on organization performance. Journal of Entrepreneurship Education, 21(4), 1-12.

Huang, C. C. (2009). Knowledge sharing and group cohesiveness on performance: An empirical study of technology $R \& D$ teams in Taiwan. Technovation, 29(11), 786-797.

Karlenzig, W. (2014), Behind Microsoft's Digital Dashboard: $K M$.

Laeeque, S. H., Babar, S. F., \& Ahmad, H. M. (2017). The integrative determinants of innovation performance: The role of learning organization and knowledge creation. Pakistan Journal of Commerce and Social Sciences (PJCSS), 11(1), 167-184.

Laeeque, S. H., \& Babar, S. F. (2017). Knowledge creation and firm performance: Is innovation the missing link? Pakistan Journal of Commerce and Social Sciences (PJCSS), 11(2), 505-523.

Laycock, M. (2005). Collaborating to compete: achieving effective knowledge sharing in organizations. The Learning Organization.

59 | This work is licensed under a Creative Commons Attribution 4.0 International License. 
Liao, Y., \& Barnes, J. (2015). Knowledge acquisition and product innovation flexibility in SMEs. Business Process Management Journal.

Mills, A. M., \& Smith, T. A. (2011). Knowledge management and organizational performance: a decomposed view. Journal of knowledge management.

Minbaeva, D., Pedersen, T., Björkman, I. (2014). A retrospective on: MNC knowledge transfer, subsidiary absorptive capacity, and HRM. J Int Bus Stud 45, 52-62. https://doi.org/10.1057/jibs.2013.56

Nawab, S., Nazir, T., Zahid, M. M., \& Fawad, S. M. (2015). Knowledge management, innovation and organisational performance. International Journal of Knowledge Engineering, 1(1), 43-48.

Nguyen, V. T., Yang, Z., \& Le, P. B. (2018). Knowledge sharing serves as a mediator between collaborative culture and innovation capability: an empirical research. Journal of Business \& Industrial Marketing.

Nikabadi, S. M. (2014). Framework for knowledge management processes in supply chain. Iranian Journal of Information processing and Management, 28(3), 611-642.

Nonaka, I., o Nonaka, I., Ikujiro, N., \& Takeuchi, H. (2015). The knowledge-creating company: How Japanese companies create the dynamics of innovation (Vol. 105). OUP USA.

Omotayo, F. O., \& Babalola, S. O. (2016). Factors influencing knowledge sharing among information and communication technology artisans in Nigeria. Journal of Systems and Information Technology.

Ramirez, A. M., \& Kumpikaite, V. (2012). Creation, Transfer and Application of Knowledge and its Importance for Business Innovation and Organizational Performance.
International Proceedings of Economics Development \& Research, 46(6), 27-31.

Ritala, P., Olander, H., Michailova, S., \& Husted, K. (2015). Knowledge sharing, knowledge leaking and relative innovation performance: an empirical study. Technovation, 35, 22-31.

Sensuse, D. I. \& Bulan, S. J., (2013). Knowledge sharing model among academic staffs in universities. Jurnal Sistem Informasi, 8(2), 133139. https://doi.org/10.21609/jsi.v8i2.335

Shahbakhsh, B. (2013). Knowledge management and its relationship with organizational performance.Interdisciplinary Journal of Contemporary Research in Business, 5(2), 141149.

Siegel, D. S. and Renko, M. (2012). "The role of market and technological knowledge in recognizingentrepreneurial opportunities" Management Decision 50 (5), 797-816.

Taghizadeh, H., \& Shokri, A. (2015). The study of knowledge management infrastructures in Islamic Azad university from faculty members' point of view (case study). Asian Social Science, 11(25), 39.

Wasko, M. and Faraj, S. (2005), "Why Should I Share? Examining Social Capital and Knowledge Contribution in Electronic Networks of Practice.," MIS Quarterly, Vol. 29 No. 1, pp. $35-57$

Yong, C. C.,Cheah, W. C., Ooi, K. B., Teh, P. L.,\& Chong, A. Y. L.(2009). Total quality management and knowledge sharing: Comparing Malaysia's manufacturing and service organizations. Journal of applied Sciences, 9(8), 1422-1431.

Yun, J.H.J. and Mohan, A.V. (2012), "Exploring open innovation approaches adopted by small and medium firms in emerging/growth industries: case studies from Daegu-Gyeongbuk

60 This work is licensed under a Creative Commons Attribution 4.0 International License. 
region of South Korea", International Journal of Technology, Policy and Management, Vol. 12 No. 1, pp. 1-19.

Zargar, E., \& Rezaee, M. (2014). The study of knowledge management effect on performance rate of employees. European Online Journal of Natural and Social Sciences: Proceedings, 2(3 (s)), pp-3061. 